\title{
Labeling or science-by-buzzwords: The semantic trap in academic research and how to get out of it
}

The social sciences are drowning in new fancy academic terms or buzzwords, labels with unprecise definitions, rebranding phenomenon that somehow seem familiar. We are all surrounded by smart cities, innovation, and sustainability. What do these terms mean that we could not express earlier? Introducing them also raises new questions, which at first may seem provocative: Are there dumb cities too, if so where? Do we carry out research at our universities that is not innovative? Does the literature on sustainability make our products more sustainable? Above all, these new fields are formulated in almost suspiciously positive terms attracting the attention of our politicians and echoed everywhere. How can anyone be against smart cities, innovation and sustainability? It must be good, important and therefore it deserves funding.

Creating new terms to describe what is mostly old and familiar problems (relabeling) is not helping move science forward but instead hindering its development as it leads the researcher to believe he or she is setting out on a new quest, while often just ignoring past literature, especially that written in French and German languages, which then suddenly does not apply. The same is true for intelligence studies. "Research" today is too often reduced to searching for articles in one of two commercial databases: Web of Science (Clarivate Analytics) or Scopus (Elsevier), basically consisting of articles that has been written during the past two generations. Here we are supposed to cite the most cites articles, even though the same ideas (but with different words) have been expressed numerous times before in older articles, books or are just common sense, so that whoever wrote the first article become popular. This then is the pyramid scheme of the brave new world of the social sciences, a system that creates academic peacocks The majority of social science researchers today are not first of all knowledgeable in say economics or business, but of how to produce articles. That is a skill that has less to do with what is happening in the real world of social behavior.

That is the price we must pay, some say, but the actual production of research also attracts very little attention outside of the circle of academics who contribute to it. Moreover, it makes our business education less relevant. Ask yourself, if today's business education was relevant, why are the Chinese outperforming the West? Why are there so few famous business schools in economically successful countries like Germany, Taiwan, or South Korea? Who teaches you how best to succeed in business life, the authors of the most cites scientific articles in business and management or the Chinse classic authors, like Confucius or Sun Tzu?

When I got interested in intelligence as a business student it was based on the notion that better information can make organizations more competitive. This was still during the first generation after the start of what was called the information age, when companies realized that information and knowledge, not physical assets, were the most important ingredients for business success. There was no internet, nor mobile phones. I was interested in the following questions:

1. How do organizations work with information?

2. What is the most effective way for organizations to work with information to obtain a competitive advantage?

3. Why are organizations not working more effectively with information?

I was interested in these questions from an international perspective, curious about the relationship between specific cultures and production. So, much like Marco Polo, I asked myself: 
4. What can we sell to other countries and what can we buy from them?

5. What is the best way of doing this?

I am still predominantly interested in these questions and Marco Polo seems to follow me in my thoughts wherever I go and seek new knowledge. I am not interested in the semantics surrounding these questions, the new terms that are introduced more as labels than to give a more exact definition of the underlying phenomenon we are looking at. To make things even worse, these new labels change, and quite frequently, in what looks like ever-shorter life cycles of social science research fields, replacing each other after quick overlaps. It is much like watching trends in the clothing industry. Suddenly you realize that your corduroy pants that work perfectly and have no holes in them need to be changed out. Your surroundings demand it.

To take a more fitting example: I was interested in how people work together with information as we started a research project on why employees hide information. Here, I am not interested in collective intelligence, competitive intelligence, co-creation, wisdom of crowds, knowledge management, complex systems, or systems theory, just to take some examples. I am first of all interested in the problem.

Many academics mix labels with theory. Theory does not mean to name labels, but to present similar problems in other studies, to say if they reached similar or different results and to try to explain why this may have been the case and what it means for our own study. This can be done almost completely without using labels.

Still, I tend to spend more time on semantics than on actual problems, very much against my own will. It's like my academic surroundings impose this on me. It seems that most business researchers fall into the same semantic trap. It's not only due to how we label problems with key words in databases, but also to the way we organize ourselves as researchers.

The process can be explained as follows: Business researchers quickly try to own the terms that they become interested in instead of focusing on the problems and problem areas that they are interested in. Instead of broadening the field, we narrow it, becoming specialists in ever smaller parts, all with their own labels. After a few rounds we are no longer in contact with business life anymore.

There is another variation of this problem and that is when the academic discipline is in close contact with industry even though it is erroneous. To me the scariest example of this is the study of economics after Keynes, which is sometimes referred to as Neoclassic economics. It seems clear to me that the major reason that banks, the financial sector and the organizations supporting this industry pay lip service to the study of modern economics is that it legitimizes a corrupt and close to bankrupt system that does little good to others outside of its own members.

Any problem can be studied from the perspective of numerous terms. Often it does not matter which term we use as there are many terms that overlap and can be relevant simultaneously. Instead of accepting this, academics strive to own the terms they chose to use and to disown others, especially those that are closely linked. As soon as we identify ourselves with one term, we start to oppose other, similar terms, treating them almost as competitors, as we often compete for the same or similar research positions and grants. New academics come along and pick their label, often by accident, for example, when adopting the preferred label of a supervisor, until each term forms or constitutes an academic tribe. These academic tribes then develop their own conferences and journals, and an internal struggle finds place, a race to establish legitimacy around an internal hierarchy most often built on the popularity (impact) of articles, and less so on the quality of the content or its relevance.

It's also possible to be in several tribes at the same time, even though academics normally have a clear preference of one above the other, simply because it's difficult to excel in more than one area. As an example, authors in the field of collective intelligence also study artificial intelligence, collective behaviour, swarm intelligence, complex systems, machine learning, human-computer interaction, multiagent systems, sustainability, information systems design, crowd work, evolutionary computation, social decision making, empathy justice, foresight, futures research, crowdsourcing, information systems network, and/or democratic theory. Collective Intelligence is used synonymously or in combination with co-creation, wisdom of crowds, opens source, social systems, and social complexity, all with their own tribes. Within intelligence studies we have sub-tribes in the form of competitive intelligence, market intelligence, competitor intelligence, business intelligence, enterprise resource planning, social intelligence, all of whom deal with the problem of collective intelligence. Close by there are the tribes of futures studies and foresight. In a corner sits the library sciences. Across the road there are the tribes of decision making, decision sciences, information sciences. All are quite familiar with the same phenomenon studied as collective intelligence. In other disciplines there are similar labels and key words, for example collective behavior in the study of sociology. The problem is that researchers seldom direct their attention outside of their own tribe. This is not only an odd scientific process, but we are witnessing an enormous waste of intellectual ability and potential. So, how do we solve it? 
To become more relevant academic research must redirect its focus from buzzwords to problems, not just smart "research gaps" in the literature. Instead of listing keywords, researchers, academic journals and academic databases should list problems (1), and the problems should be stated in full sentences (2) using as few (3) and as simple words as possible (4). We should also insist on clear, mutually exclusive definitions. By searching for problems instead of labels it will become much easier to find relevant research across different labels and disciplines.

We need to be much stricter when admitting new labels. If a new term is not exact and not much different from a previous term it should be declined. Focus should be on what the Germans since the 19th century understand by "verstehen", as the "interpretive or participatory" examination of social phenomena, not on coining new terms. Today new terms often come to life because we did not read enough, or we thought more about internal marketing and our own self-promotion instead of focusing on problems that are important for humanity. We are all guilty of this to a certain degree as it's difficult to escape the logic trap that is our current social science research system.

We need to instill a new critical process of thinking by asking: What problem does this field of study lay claim to? Are there other studies that lay claim to the same problem? If yes, go back to the previous field. If it does not exist anywhere, and if you are 100\% certain, only then can you coin a new term after consulting with your peers. This process would lead to the merger of most of all existing social science research today. The same could then be done with conferences and academic journals. Larger academic groups will again improve the quality of journals and conferences, thus improve the advancement of science.

To complicate things further labels are sometimes decided outside of academia. The world of business is basically changed by its practitioners, not by academics. As an example, competitive and market intelligence is now often replaced by competitive and market insights (CMI) in many major companies. The intelligence label was always problematic and the association to the world of spying never quite washed off. It did not help that many successful business intelligence companies functioned more as private eyes with aggressive methods despite organizations like SCIP setting standards to the contrary. Many were also skeptical to what they understood as an Anglo-Saxon and predominantly American agenda to spread the practice of industrial espionage advocated by consultants centered around Langley.

The difference between the term intelligence and insights is not significant. It basically means the same: valuable information, need-to-know for the competitiveness of the firm. Put differently, there is hardly any part of insights that cannot be seen as intelligence and vice versa. However, it could be argued that market insight is a broader take on business information. It could be said that it brings together a wider group of fields, both practitioner and academics, some of whom were left behind in the process when smaller academic tribes were created. Market researchers, business intelligence specialists and all kinds of information scientists are now lured back together under the umbrella of earlier pioneers like the visionary businessman Alvin Toffler, the mathematician Claud Shannon, and Gabriel Naudé, the father of library sciences, just to give a few examples. The "insight people" have already started to form their own group. Academics are likely to follow. Other academics are already finding themselves sitting in groups that are no longer relevant wondering what happened.

The academic projects that are the most successful will always be those that follow the development in business life. The discipline of digital marketing is a good example. Digital marketing is fundamentally different from the old "brick marketing," to the point that if you do not understand its logic today then your education is not relevant any longer. It took academia a long time to understand this and for a few years the whole discipline of marketing was terribly far behind reality. The advancement of the field still almost exclusively finds its place in business organizations. Academics are mostly trying to run after and catch up with the practitioners in this field of study. One reason for this is that advancements in digital marketing demand substantial IT infrastructure that academics do not have easy access to. The situation is similar in business intelligence, which is basically about new software today. The leading AI experts do not work in academia but in the major tech companies.

It is all about being relevant and useful. In intelligence studies there is a demand on us that we integrate business practices with more technology (hardware and software). Only then can we hope to make real academic contributions in this field. We stand in front of an almost awkward situation: The intelligence field has never been more relevant in the history of mankind as information has become the most important ingredient for competitive advantage. And the more information, and the better information, the more valuable the company. All the new and major MNEs around us are living proof of this, whether it be Alphabet (Google), Netflix, Spotify, Facebook or Alibaba. To understand and be able to contribute to this domain we must be interested in the same problems that they are trying to solve. To this aim the labels are often just distractions, asemantic trap.

The first three articles in this issue deal with different forms of literature and domain analysis, linking competitive intelligence to other fields of study. 
The article by Miguel-Ángel García-Madurga and Miguel-Ángel Esteban-Navarro entitled "A project management approach to competitive intelligence" examines the relationship between competitive intelligence (CI) and project management (PM).

The article by Mouhib Alnoukari is entitled "An examination of the organizational impact of business intelligence and big data based on management theory". According to a literature analysis done by the authors, both the dynamic capability view and resource based theory are the most dominant organizational theories that have been used to investigate BI \& BD related issues.

The article by Stefan Zwerenz is entitled "The linkage between competitive intelligence and competitive advantage in emerging market business - a case in the commercial vehicle industry". The results of this case help businesses to improve CI, its constructs, its products and process for a better linkage to competitive advantage and firm performance.

The last two articles are related to accounting. The article by Phan Thi Bao Quyen and Nguyen Phong Nguyen entitled "The impact of perceived accounting benefits on the enterprise resource planning success: the mediating role of effective system use" studies the accounting benefits of adopting ERP systems. The authors conclude that there is support for perceived accounting benefits of ERP systems on enterprise success. They also argue that this conclusion is supported by effective system use.

The article by Muhammad Ikbala, Irwansyaha Irwansyaha, Ardi Pamintob, Yana Ulfaha, and Dio Caisar Darmac entitled "Financial intelligence: Financial statement fraud in Indonesia" deals with the problem of financial fraud in Indonesia. The results of the non-parametric relationship analysis show that although there is a possibility that the more experienced the auditor will be the more able to detect fraud and manipulation in the organization, the relationship is relatively weak. Findings also show that all auditors who have a CFE certificate find it easier to find fraud in the company.

With this issue JISIB celebrates 10 years of publications. During the first years it was difficult to get enough quality articles for every issue, but now we get interesting and relevant articles submitted every week and reject more than $80 \%$.

As always, we would above all like to thank the authors for their contributions to this issue of JISIB. Thanks to Dr. Allison Perrigo for reviewing English grammar and helping with layout design for all articles. Take care in these strange times when a new virus, COVID-19, is ravaging the planet.

On behalf of the Editorial Board,

Sincerely Yours,

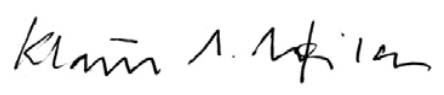

Prof. Dr. Klaus Solberg Søilen

Halmstad University, Sweden

Editor-in-chief 